\title{
The Realization of Intelligent Charge Control System Based on The Marketing Service System and The Electricity Collection System
}

\author{
Sheng Zhou ${ }^{1, a}$, Xianhui $\mathrm{Li}^{2,3, \mathrm{~b}}$, Gang Zhen ${ }^{1}$, Shengpeng $\mathrm{Ji}^{2,3, \mathrm{c}}$, Wei $\mathrm{Li}^{1}$, \\ Yongsheng Wang ${ }^{2,3}$, Yang, He ${ }^{2,3}$, Weidong Tang ${ }^{1,2}$, Jun Chen ${ }^{4}$ and Ping Lou ${ }^{4}$ \\ ${ }^{1}$ State Grid Zhejiang Electric Power Reseach Institue, Hangzhou 310014, China \\ ${ }^{2}$ NARI Group Corporation, Nanjing 210000, China \\ ${ }^{3}$ China Realtime Database Co.,Ltd., Nanjing 210000, China \\ ${ }^{4}$ State Grid Huzhou power supply company, Huzhou 313100, China. \\ azhousheng851114@163.com, ${ }^{b}$ 275188730@qq.com ,"jishengpeng@sgepri.sgcc.com.cn
}

Keywords: Marketing business system Power acquisition system Intelligent charge control Advance payment master station Terminal electric meter

\begin{abstract}
In view of the present situation of the popularization and application of the power supply enterprise smart meter, smart meters, marketing business system and analysis of the electric energy data acquire system, current prepaid business and customer service business model have been unable to adapt to the new technologies and new ways through the proposed marketing business system and the implementation of the electric energy data acquire system of intelligent charge control system based on to help the power supply enterprise to enhance the electrical charge risk control ability and service level, strengthen the fine management of power supply enterprise.
\end{abstract}

\section{Introduction}

With the advancement of smart grid construction, power supply enterprises began to fully build a collection system of intelligent power consumption information aim for "full coverage, full collection, full charge control", to realize the transformation from the simple electric quantity collection to the user side comprehensive data collection, the user's electricity management, to achieve the power grid applications of efficient, economical and intelligent.

The construction of Big Data and implementation of cloud computing for power supply enterprises, it provides the storage, centralization, integration, calculation, sharing and analysis of the real-time and historical data formed by the various business applications in the production process, at the same time provide a unified standard of access, is an infrastructure of information that provides technical support for green power grids and operations management applications-particularly cross-disciplinary and cross-functional, integrated business applications that provide real-time historical data.

According to the company's plans of smart table to promote, the new business model produce a revolutionary impact and change to the traditional business model of marketing, traditional business acceptance, meter reading, accounting, fees, reminder fees, stop power business, metering asset management, customer service business models have been unable to adapt to the needs of new technologies and new ways; On the other side, with the development and maturity of smart meter technology and the improvement of user-side integrated data collection, it will create conditions for the company to improve the power consumption risk control ability, enhance the customer service level and other fine management, construction cost control management system to fully support the marketing fee control business development is imperative.

Based on the modern information communication means, relying on high-efficient large data storage and cloud computing processing technology, combining the electric power marketing application system and the electricity information collecting system, the intelligent electric charge control combines the advanced electric marketing business concept, realize all functions of the 
remote or local prepaid user fee control service from the master station, the terminal, the meter three links.

\section{Intelligent cost control architecture}

Intelligent charge control system architecture is divided into four layers: the terminal layer, communication layer, business and data processing layer, user layer, as Fig.1 shown[7]:

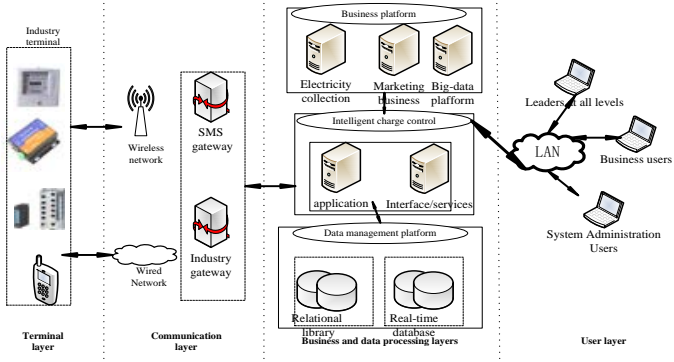

Fig. 1 Intelligent charge control architecture

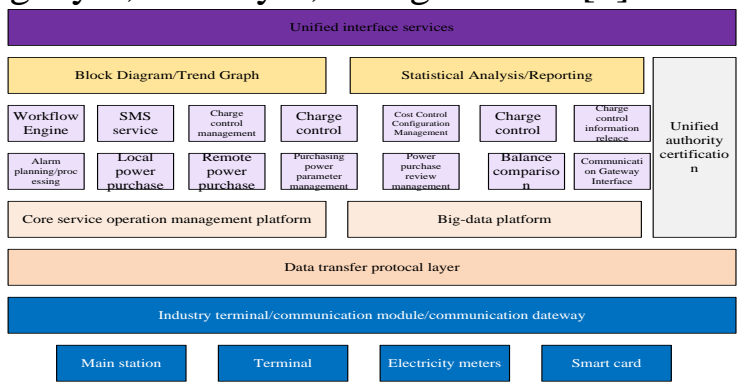

Fig. 2 Intelligent charge control system function

Terminal layer:Covering the power industry can involve all the terminal equipment, such as the main station, terminals, meters and so on; All terminal equipment through a variety of wired and wireless network and intelligent charge control system communication, reporting terminal data and the implementation of the platform issued an order.

Communication layer:Including the support of power terminals of a variety of devices, such as wireless base stations, SMS gateways, industry gateways, but also includes the Internet, VPN, LAN and so on. The main function of the communication layer is to provide transparent transmission of data, which is the communication bridge between the terminal layer and the intelligent control system layer.

Business and data processing layers:Includiing the access, calculation, storage of the Power acquisition syste's real-time data;The accounting, cost of configuration information of Marketing business system's synchronization access;Intelligent charge control system for the cost control management.

User layer:Involving the provincial network at all levels of leadership, the functional business sector, user management and so on. Log on the platform at all levels to view the statistics of various applications, functional departments at all levels log on the platform for cost control management, user login platform for platform management and maintenance.

\section{Intelligent charge control system function}

The function structure of intelligent charge control system is shown in Fig.2.

\subsection{Local power purchase}

Card table power purchase: To achieve from the marketing business application system to obtain the user's electricity price, arrears and other information, to determine whether the sale of electricity, calculate the minimum amount of electricity sales and receive the amount of electricity sales, the user number, asset number, purchase amount and purchase Electricity and other information written to the user card, and print out the relevant bills, while the number of purchase power purchase, purchase power purchase information such as the amount of electricity.

\subsection{Remote power purchase}

Remote power sales: Smart table local charge control users through business counters, online banking, third-party collection channels for remote power purchase channels; and the purchase of electricity information issued to the smart table[8].

\subsection{Purchasing power parameter management}

Electricity price adjustment: To achieve the intelligent control of the local user control of the meter to adjust the power price settings; purchase of electricity parameters adjustment issued: the realization of electricity prices, meter reading cases, transformer ratio than the purchase of electricity 
parameters adjustment issued.

\subsection{Power purchase review management}

Job Review: For dispatching of electricity price adjustment, dispatching of electric parameters adjustment, and adjustment of dispatching case, it is necessary to carry out manual processing for unsuccessful work, and the job is handled by designated personnel. According to the results of the "job review", the "price adjustment information", "power purchase parameter adjustment information" and "meter reading day adjustment information" which have failed to be issued by the remote control are programmed through the management card, and the user parameters are read and written by the card Information on-site settings.

\subsection{Balance comparison}

Measurement strategy configuration: According to the intelligent management of the user needs to develop various types of user measurement task rules [9].

Calculation of Electricity: According to the measurement task information, the electricity calculation task is launched from time to time, and the electricity consumption is calculated by the meter reading data collected by the electric information collecting system; And the user who has abnormality in the electric power consumption calculation enters the abnormal processing.

Balance comparison : According to the electricity charge of electricity, combined with real-time balance of the system in advance to calculate the user real-time / quasi-real-time remaining amount.

\subsection{Charge control management}

The master station calculates the remaining power charge based on the user's payment information and the data of the user's power meter collected at regular time, when the remaining tariff is equal to or lower than the alarm threshold, the main station issued a reminder alarm command to inform the user timely payment. When the residual power is equal to or lower than the trip threshold, the master station issued a trip control command to inform the user and cut off power supply. After the successful payment by the user, the master station shall promptly issue the allowable closing command within the specified time to allow the closing.

The master station can input and store the electric energy rate period and rate and the charge control parameters including the purchase order number, the payment value, the alarm and trip threshold according to the payment information of the user, and deliver the terminal and the electric energy meter. When you need to control the user, the terminal issued a cost-control input command, the terminal according to the alarm and trip threshold, respectively, the implementation of alarm and trip. After successful payment by the user, the master station shall promptly issue the permitting closing command within the specified time to allow closing.

\subsection{Cost Control Configuration Management}

Fee control input debugging, the system from the marketing business system to obtain payment information, and the initial purchase of electricity debugging work for the cost control inputs and the lifting of the provision of technical support. If the initial purchase of electricity should be terminal control function of debugging, if debugging is not successful, then trigger on-site process.

The control parameter is issued to the user terminal which carries out the terminal and the meter charging control, and the pre-purchase electric control is executed by the remote control technical means to the pre-purchase electric control parameter to the control terminal.

User balance view, the system can call the user terminal to check the remaining balance of payment or power and display.

\subsection{Charge control}

For the main station to implement the cost control of customers, according to customer fee control situation through remote control of technical means, according to pre-set tripping times to control. Including the pre-purchase of electric control input and pre-electric control cancellation.

\subsection{Fee management fees}

The system can control the arrears according to the requirements of remote control through technical means to put into force or lift the reminder of the alarm, reminders fee power,Prompts the charge control to receive, The control parameters are issued.

\subsection{Cost control condition information release}


The system can inquire the request according to the received user terminal working condition, call terminal conditions, and release the user terminal operating mode data.

\subsection{Charge control statistics}

The system can control the situation of charge control. View the number of cost-controlled users in the region where the operator is located. As well as the number of users to meet the query conditions, as well as the amount of consumption, the total balance, terminal conditions and other information.

\subsection{Communication Interface}

The method comprises the following steps: sending the data to the terminal or the meter through the wireless / wired way of the master station; uploading the data to the master station by the terminal or the meter wirelessly / wiredly; and analyzing and processing the RS485 communication interface protocol of the meter.

\subsection{SMS service}

SMS service is to better serve the user, user-friendly and recharge. There are cost reminders SMS, cost alarm SMS, the same period and the cost of tips SMS and so on[10].

\subsection{Workload engine}

The realization of the workflow can be configured to manage and automatic flow control.

\section{Conclusion}

Based on the marketing business system and the power acquisition system of the intelligent control system, through the user data acquisition, real-time data collection, data transmission, cloud computing, terminal billing, remote monitoring, two-way interaction, user experience and other processes to manage and control the user prepaid, Realization of intelligent charge control function, power supply enterprises not only changed the old "copy", and nuclear power acquisition process, also lead to reliable control after paying income loss unreliable a prepaid, but also to enhance the fine management of the power supply enterprise has provided technical means.

\section{References}

[1] Joachim Haeusler. Follow the money: using payment behaviour as predictor for future self-exclusion[J]. International Gambling Studies,2016,162:.

[2] Lešek Franek,Ladislav Šastný,Petr Fiedler. Prepaid energy in time of Smart Metering[J]. IFAC Proceedings Volumes,2013,4628:.

[3] Péter Kádár,Andrea Varga. The role of the Smart meters in the energy management systems[J]. IFAC Proceedings Volumes,2012,4521:

[4] Birgit Mack,Karolin Tampe-Mai. An action theory-based electricity saving web portal for households with an interface to smart meters[J]. Utilities Policy,2016,:

[5] Xiufeng Liu,Per Sieverts Nielsen. A Hybrid ICT-Solution for Smart Meter Data Analytics[J]. Energy,2016,:

[6] Ali Al-Wakeel,Jianzhong Wu. K-means Based Cluster Analysis of Residential Smart Meter Measurements[J]. Energy Procedia,2016,88:.

[7] Takamasa Iryo. Day-to-day dynamical model incorporating an explicit description of individuals' information collection behaviour[J]. Transportation Research Part B,2015,:.

[8] Fontina Petrakopoulou. On the economics of stand-alone renewable hybrid power plants in remote regions[J]. Energy Conversion and Management,2016,118:.

[9] Gerbino Peter G,Griffin Elizabeth D,Zurakowski David. Comparison of standing balance between female collegiate dancers and soccer players.[J]. Gait \& Posture,2007,264:.

[10] J. Matharu,B. Hale,M. Ammar,P.A. Brennan. Short message service (SMS) texting as a method of communication during on call: prevalence and experience of medical staff in a large acute NHS Trust in the UK[J]. British Journal of Oral \& Maxillofacial Surgery,2016. 